\title{
EL HORIZONTE ESTÉTICO DEL HOMBRE MEDIEVAL LA PERSPECTIVA TOMISTA
}

\author{
Abelardo Lobato, $O P$
}

\begin{abstract}
RESUMEN
Para obtener una idea aproximada del horizonte estético del hombre medieval, es preciso referirse a la relación de la estética con la cultura, a la antropología subyacente, y a los diversos campos en los cuales el hombre descubre la belleza. El hombre medieval se relaciona con lo bello en el orden objetivo de las realidades del mundo, en la forja de la propia personalidad mediante las virtudes, y en el campo de las artes útiles y bellas. Tomás de Aquino es un óptimo guia para descubrir el horizonte estético del hombre medieval. El artículo indica las etapas de este recorrido estético en el mundo objetivo, subjetivo y proyectivo. La primacía corresponde al logro de la belleza en el ser humano mediante la adquisición de las virtudes, de modo especial las de la vida contemplativa, para lo cual disponen las morales, y las artísticas.
\end{abstract}

Palabras clave: Horizonte estético, Objectum, Subjectum, Projectum

\begin{abstract}
To get approximative idea of the aesthetical horizon of the mediaeval man one has to refer to the relation between aesthetics and culture, to its subjected anthropology and to the various ground in wich man discovers beauty. The mediaeval man is related with beauty in the objective order of the realities of the world, in the moulding of one's personality through virtues and in the field of useful and beautiful arts. Thomas Aquinas is an excellent guide for discovering the aesthetical horizon of the mediaeval man. The article shows the stages of this aesthetical course in the objective, subjective and projective world. The supremacy conforms with the attainment of beauty in the human being through acquisition of virtues, particulary those of contemplative life, owing to wich the moral and artistical ones adjust.
\end{abstract}

Key words: Aesthetical horizon, Objectum, Subjectum, Projectum.

La comprensión adecuada de la estética de un período concreto implica tener presentes tres factores constitutivos: su relación con la cultura, su fundamentación en lo humano y el abanico de sujetos a los que se extiende. Este marco se puede aplicar a la estética medieval. Tomás de Aquino, por la penetración de sus intuiciones, y su capacidad de síntesis puede servirnos de pauta para el estudio de lo que designamos como horizonte estético medieval. 


\section{CULTURA Y ESTÉTICA}

El hombre es un ser natural que se realiza en la cultura. Hoy hablamos de la cultura en un sentido de totalidad envolvente, de una cierta atmósfera en la cual respira a sus anchas, por cuanto integra los elementos que completan las carencias de su naturaleza. El mito platónico del diálogo Protágoras describe el elemento cultural en el asalto de Prometeo al Olimpo de donde roba a los dioses las artes y las ciencias, los valores y las virtudes, la relaciones con cuanto trasciende la materia. ${ }^{1}$ La cultura, como totalidad, le afecta en su mismo ser. Por el hecho de tener una naturaleza muy compleja, repleta de dimensiones y posibilidades, el hombre se desarrolla gracias a la cultura. Mientras que la esencia y naturaleza humana, aún siendo la fuente de todo dinamismo, se presenta con una gran estabilidad a lo largo de la historia, la cultura es de suyo multiforme, inestable, cambiante, se encarna en lenguas, en costumbres, y ofrece soluciones en conflicto a idénticos problemas que cada día se presentan a los hombres.

La dimensión estética, si bien brota de la naturaleza humana, capaz de la belleza, es típicamente cultural. Y por ello cada época, cada grupo cultural, la percibe y la expresa diversamente.

No faltan quienes piensan que la estética no entra en el horizonte de la cultura medieval y que en esta materia tiene poco o nada que enseñar. El mismo Croce, que divulgaba breviarios de Estética, tiene sus dudas al respecto. ${ }^{2}$ Pero la realidad es bien diversa, y está bien documentada . ${ }^{3}$ El pensamiento cristiano ha tenido en esa época su mejor expresión teologal y antropológica. Por ello yo creo de gran interés, tanto para conocer más a fondo esa cultura medieval, como para aprender la lección que nos ha dejado, poner de relieve lo que llamo el «horizonte estético» del hombre medieval y verlo reflejado en la obra de Santo Tomás de Aquino. Al iniciar esta reflexión estética me parece conveniente precisar su sentido.

La imagen del «horizonte» es antigua y fue muy usada en las escuelas neoplatónicas para designar al hombre mismo, la realidad que Demócrito llamaba «microcosmos», porque el alma humana era como el ópı Yov o confinium entre los dos órdenes del ser, la materia y el espíritu ${ }^{4}$. En la filosofía actual esta imagen del «horizonte» ha vuelto a tener vigencia, porque se presta a una visión dinámica de la realidad humana. Es un dato de experiencia vivida lo siguiente: que en el orden físico el hombre se encuentra, velis nolis, en el centro del contorno que le rodea, el cual es al mismo tiempo su mundo a los ojos y a la mano, y es su límite. Hombre y horizonte caminan a la par. La cultura en que nos hemos forjado va con nosotros, la llevamos sobre los hombros y nos lleva de muchos modos. Hablamos un lenguaje, y al mismo tiempo el lenguaje habla en nosotros. Todo hombre es al mismo tiempo sujeto y objeto cultural. Cada época histórica vive inserta en un horizonte estético, de aproximación o lejanía de la belleza.

1 Platón, Protágoras, 320d-322b.

2 B. Croce, Estetica, Bari, 1946 p. 192. A propósito de Santo Tomás dice que sus ideas acerca de la belleza son acertadas, pero escasas, dispersas, muy generales.

3 Cfr. J. Le Gof, L'arte e la società medievale, Laterza, Roma-Bari, 1977; R. Pernoud, Medioevo, Un secolare pregiudizio, Buompiani, Milano, 1983. E. De Bruyne, Êtudes d'esthétique médiévale, De Tempel, Brugge, 1946.

4 Cfr. A. Lobato, «Anima quasi horizon et confinium», en el vol. "L'anima nell'antropologia di San Tommaso», Massimo, Milano, 1987, pp. 53-81. 
El horizonte estético de la era llamada moderna se ha ido reduciendo a partir de Kant y de Hegel. El mundo real, las cosas tal cual son en ese mundo, quedan sustituidas por imágenes y fantasmas, por pensamientos y razonamientos. No hay posible salida del sujeto. En esa situación , como concluye John Locke, «es evidente que nuestro conocimiento solo versa acerca de las ideas». ${ }^{5}$ Por esa via de alejamiento de lo real, la hora moderna ha dejado de lado la belleza objetiva y se contenta con los gustos y valores culturales. El horizonte estético se ha hecho más intenso, pero ha quedado empobrecido. El problema estético sigue la parábola de la caída del ser y del hombre, porque siempre cabalga a sus espaldas ${ }^{6}$.

Al hablar del horizonte estético en la cultural medieval cristiana nos referimos a este horizonte que integra todas las relaciones del hombre con la belleza, contemplada en el mundo, conquistada en el hombre, reflejada en las obras del arte. Es el horizonte reflejado en la obra de De Bruyne ${ }^{7}$.

\section{HOMO, CAPAX PULCHRI}

La obra de Tomás de Aquino está salpicada de alusiones al horizonte estético. Basta abrir el Index thomisticus para comprobar en los vocablos que usa el aprecio que tiene de la belleza en relación con el ser. El investigador F.J. Kovach ha realizado el doble itinerario de la estética de Tomás, el analítico y el sintético, y ha dejado en claro no solo la continua referencia a la belleza sino también la conexión con el bien y con el ser en todas sus dimensiones. ${ }^{8} \mathrm{El}$ ser humano no solo vive inmerso en un mundo admirable, que en cierto modo es un espejo de quien lo ha creado para el hombre, sino que abriga la certeza que el creador ha querido contar con él en su gobierno y desarrollo. Esta dignidad lo eleva a participar en la marcha del mundo en el cual está insertado. El mundo tiene en verdad un principio antrópico, y al hombre se le confía una tarea estética que debe desarrollar en las dos dimensiones que le competen, la contemplativa para la cual está bien proporcionado, y la factiva, que se le encomienda cuando se pone en sus manos y a su alcance el dominio de la realidad. Desvelar la belleza escondida en los entes, hace posible prolongarla en sí mismo y en los objetos que fabrican sus manos. El homo aestheticus de Tomás de Aquino no solo es capax pulchri, porque descubre lo bello a su alrededor, sino porque lo produce en cuanto es también creador de belleza.

La relación con la belleza es singular y distingue al hombre entre todos los seres del cosmos. Tomás afirma que el hombre es el único ser del cosmos que percibe y se deleita en la belleza en cuanto tal: Solus homo delectatur in ipsa pulchritudine. ${ }^{9}$ La belleza requiere un sujeto capaz de gustar un placer desinteresado, amar lo bello por sí mismo. En la estructura de lo humano se da esta

\footnotetext{
5 J. Locke, An Essay concerning Human Understanding, I. IV, c. I.

6 Cfr. A. Lobato, Cristianesinto nella posmodernità, Bologna ESD, 1994.

7 Cfr. E. De Bruyne, Estudios de Estética medieval, B.H.F. Gredos, Madrid, 1958. Una visión de totalidad sobre la estética medieval la ofrece V. Stella, en la voz «Estética» de la «Enciclopedia dell'arte medievale». Vol. VI, Roma, 1995, pp.29-34.

8 F.J. Kovach, Die Aesthetik des hl. Thomas von Aquin, Berlin, Walter de Gruyter, 2 vols. 1961.

9 Santo Tomás, ST, I, 91.3 ad 3.
} 
posibilidad. Tomás lo pone de relieve en fórmulas que tocan la esencia de lo humano y recuerdan expresiones análogas de Aristóteles: Por naturaleza el hombre desea la belleza, ama lo bello. ${ }^{10}$ Estos preámbulos nos brindan un fundamento suficiente para el desarrollo de una teoría del Homo aestheticus en Santo Tomás de Aquino. En realidad Tomás vive en ese horizonte en una triple dimensión, existencial, filosófica y cristiana.

En los años en que Tomás se siente vinculado como oblato a la familia benedictina, tiene el privilegio de entrar en el proceso de la formación literaria, de estudiar y de aprender a fondo, durante 9 años, las llamadas artes liberales, entre las cuales hay que contar la poética, la retórica, y la música. Este bagaje cultural formará parte de su cultura posterior. Tomás deja pruebas de su estima por algunos escritores clásicos como Cicerón, a quien lee y cita con agrado. ${ }^{11}$

Las huellas más valiosas que nos ha dejado Tomás de su dimensión estética, pertecen al período más largo de su vida, cuando se integra en la familia dominicana. Tomás podría decir como Agustín, que los cantos en el coro con la música gregoriana, le arrancaban lágrimas de emoción y ternura, de modo especial cuando en las Completas se cantaba la antífona Media vita in morte sumus. El dato más cierto que tenemos de las cualidades estéticas de Tomás, es el de la composición del Oficio del Corpus Domini, a petición del Papa Urbano IV, quien con motivo del milagro de Bolsena, extiende a toda la Iglesia la celebración de la fiesta. Alguien daría toda su obra poética a cambio de haber escrito una sola de las estrofas de los himnos que ha compuesto Tomás. La liturgia latina los ha incorporado, los conserva y los canta con los ritmos que Tomăs les ha impuesto. ${ }^{12}$

La estética más valiosa de Tomás, la que todos admiran, es la que brota de sus obras, que no solo buscan exponer la verdad, que es el oficio que Tomás ha asumido, sino que están concebidas y realizadas con un orden admirable. Es la categoría del orden la que les confiere el esplendor de la forma mentis que Tomás imprime en todo cuanto toca. Como auténtico sabio, Tomás ha sacrificado las preferencias subjetivas, a este esplendor de la verdad que se impone por su fuerza y puede decirse la clave de su pensamiento. ${ }^{13}$

El humanismo vivido es un válido itinerario para el desarrollo de un humanismo pensado. Aristóteles le confirmaba en esta senda, con sentencias profundas, como ésta: «Uno juzga de las cosas conforme a su estilo de ser»: Qualis unusquisque est, talis et finis videtur ei! $!^{14}$. Uno de sus estilos de responder a la pregunta por el hombre, es el que procede desde abajo. Esta vía ascendente es apta para describir al hombre en las afinidades que tiene con los diversos grados del ser, y en la diferencia que lo separa de todos los otros. Cuando se capta la diferencia, se logra entender la esencia del hombre, que siendo el microcosmos, tiene el don de reunir en verdadera unidad de modo intensivo cuanto en el macrocosmos se encuentra disperso.

10 Santo Tomás, In Psalm. 26, n.3: «naturaliter homo desiderat pulchritudinem». In Psal, 25, n 5: «Homo amat pulchritudinem».

11 Cfr. P. Torrell, Initiation a saint Thomas d'Aquin, Ed. Cerf, Paris, Fribourg, 1993, pp. 6-10.

12 Cfr. P.M. Gy, "L'Office du Corpus Christi et S. Thomas d'Aquin. Etat d'une recherche» en el vol. «La liturgie dans l'histoires Paris, 1990, pp. 223-245.

13 Cfr. S. Ramírez, De ordine placita quaedam thomistica, Salamanca, Editorial San Esteban, 1963.

14 Aristóteles, III Ethic. 7. 1114 a 32-b 1. 
Para la comprensión del hombre, desde abajo, en todo su realismo, Tomás recurre a las intuiciones bien fundadas de Aristóteles, que conservan todo su valor. Basta enumerar tres que son como los pilares de su antropología.

1.- El hombre es un compuesto de dos elementos contrarios que se unen de modo sustancial como materia y forma, es decir de cuerpo y alma. El cuerpo es de esencia del ser humano, se le ha dado para su perfección, y es al mismo tiempo su límite. La vida estética se realiza gracias a la sensibilidad que tiene su asiento en el cuerpo. No hay estética sin el cuerpo y la sensibilidad.

2.- El alma es forma sustancial del cuerpo, pero no es forma material, sino emergente por su condición espiritual. Como tal está en todo el cuerpo y es principio vital en los tres órdenes de animación, el vegetal, el animal, el humano.Los sentidos superiores, la vista y el oído, tienen la máxima importancia en la vida estética. El sentido radical es el del tacto. Tomás descubría, con Aristóteles la afinidad entre el sentido del tacto y la capacidad cognoscitiva del hombre. Sin duda se aplicaba la sentencia aristotélica: los que tienen un sentido agudo del tacto y carnes blandas, están mejor dispuestos para el ejercicio de la inteligencia, y de la vida estética: molles carnis, bene aptos mente esse videmus. ${ }^{15}$

3.- El desarrollo del hombre se lleva a cabo mediante el despliegue de las posibilidades del alma en el cuerpo. El alma humana está abierta a la totalidad, mediante sus potencias y sus órganos, se abre al infinito. Aristóteles lo ha expresado en fórmula imperecedera, anima est quodammodo omnia. ${ }^{16}$ Tomás lo ha aplicado en todos los órdenes de lo humano. La vida estética es signo de esta apertura única del alma humana, que por la mente penetra en el mundo objetivo del conocer y del amar, y por la mano, como instrumento conjunto maneja toda clase de instrumentos y da origen al mundo de los productos en la materia. El hombre es animal racional, y por ello la inteligencia y la razón son la clave de lo humano. Bonum hominis est secundum rationem esse. ${ }^{17}$

Desde esta antropologia filosófica, Tomás pone las bases del hombre estético, que vive de los sentidos y sus objetos, en la corporeidad y los trasciende en la vida interior que desarrolla en las dos vertientes del conocer y apetecer, para culminar en el ejercicio del intuir y gustar, propio del hombre espiritual. ${ }^{18}$

La via teológica, la que se propone ver las cosas desde Dios, es para Tomás la decisiva, porque es el modo de alcanzar la verdad toda entera del hombre, y esta es la via que Tomás ha elegido para su oficio de maestro. Desde la revelación se obtiene la visión del ser humano desde arriba, en orden descendente. Esta visión la ofrece la palabra de Dios en la tradición y en la Escritura, y la trata de entender la teología. Tomás teólogo descubre el humanismo integral, el que se revela en Jesucristo, imago Dei, y se participa en todos los hombres, creados por Dios a su imagen. El teólogo Tomás recoge la tradición cristiana de los tratados De Homine, que inicia Nemesio de Emesa,

\footnotetext{
15 Aristóteles, II De Anima, 9, 421 a 26

16 Aristóteles, III De Anima, 8, 431 b 21

17 Santo Tomás ST, $I I-I I, 47,6$. Cfr. L. Elders, Bonum animae humanae est secundum rationem esse», en «Rivista Teologica di Lugano» 4(1999) pp. 75-90.

18 Una exposición más amplia de estos principios del filosofar sobre el hombre en Tomás de Aquino la hemos realizado en otros trabajos más específicos: Cfr. A. Lobato, El hombre en cuerpo y alma, Edicep, Valencia, 1994;» La humanidad del hombre en santo Tomás, en el vol. «San Tommaso d'Aquino, Doctor Hunanitatis», Roma, LEV, 1991. pp. 51-61.
} 
en los cuales se tiene en cuenta no solo el origen del hombre por creación, al final de la obra de los seis días, sino la estructura esencial, en la cual la carne tiene un papel esencial. Pero más importancia aún tiene para Tomás la revelación sobre el origen del hombre en el misterio trinitario, el pricipio antrópico, el destino de ser llamado a conformarse con el Hijo, la interioridad de cada sujeto obra del amor de Dios, la condición de ser libres porque el Espíritu habita en el hombre y Dios ha querido hacerlo su morada, la dignidad personal por ser a imagen de Dios, el destino eterno en comunión con Dios, donde el cuerpo humano alcanzará la máxima expresión de la belleza.

Desde esta perspectiva Tomás pone de relieve algunas verdades que tienen repercusión en la estética medieval: el ser humano se sitúa en el centro del universo; el cuerpo humano está dotado de la máxima perfección entre los cuerpos; todo hombre está llamado a la adquisición de las virtudes mediante las cuales puede recobrar el esplendor originario de la forma; el ser humano está destinado a cooperar con el Creador y así logra ser un singular artista que no solo da origen a obras útiles y bellas, sino que él mismo debe ser llevado a la plenitud de la perfección. Esta perspectiva del hombre desde el misterio de Dios presenta la profunda armonía de los contrarios, la grandeza y la pequeñez, el esplendor y la miseria. Todo ello lo expone Tomás de modo admirable en la glosa que hace del salmo 8.El hombre es una maravilla de la creación cuando se contempla en los dos ejemplares que han salido de la manos de Dios, en Jesucristo, el más hermoso de los hombres, y en Adan y Eva.

En esta grandiosa visión teologal del hombre tiene su adecuado fundamento el horizonte estético tomista. ${ }^{19}$ Tomás nos ofrece una antropología que posibilita la comprensión del homo aestheticus, del hombre destinado a percibir la belleza, del homo capax pulchritudinis. ${ }^{20}$

\section{LOS TRES ITINERARIOS DE LA ESTÉTICA MEDIEVAL}

Desvelar el horizonte estético del hombre lleva consigo conocer la capacidad humana de recibir y asimilar, de actuar y transformar cuanto acontece en su mundo. Esa condición humana de no poder evadirse de ser el centro y de estar sometido a los influjos de cuanto le rodea puede describirse con la hermosa y fecunda palabra latina del verbo iacere, estar ahí, estar como en el suelo, como «arrojado», «yecto», estar como en su lecho, en su centro, en su lugar.

En esta peculiaridad está la clave de la «situación» humana, de su estar arrojado, de estar en el mundo y no ser del todo del mundo, y por ello de su capacidad de relación con la belleza. Por su apertura sensible recibe y se abre al mundo y en esa interacción tiene su principio la maravilla del conocimiento, la experiencia de mundo. En su condición de estar arrojado en medio del horizonte, el hombre mismo es objeto y le sale al paso todo el cosmos, de modo objetivo. No hay pasión sin acción, no hay ser en el mundo sin acción propia. El ser es ante todo acto y por ello ejerce sus actos. Mediante su actividad lo que era solo objeto, se transforma en sujeto. Y lo que era solo un mundo

19 La glosa que Tomás hizo en Nápoles en el último año de su magisterio, al salmo 8, ocupa un lugar de relieve en la Introducción al tratado El hombre en cuerpo y alma, Valencia, Edicep, 1994. Esta glosa condensa de modo magistral la antropologia esencial de Santo Tomás, desde este punto de vista teologal. Cfr. A. Lóbato, ibid. p-31-71.

20 Cfr. A. Lobato, «La humanidad del hombre en Santo Tomás de Aquino», en «San Tommaso d'Aquino Doctor Humanitatis», Studi Tomistici, 40, LEV, 1991, pp.51-82. 
dado se abre a la posibilidad de ser un mundo recreado. La palabra apropiada sería projeto, que corresponde a las dos anteriores objeto, lo que nos sale al paso, sujeto, aquello que va con cada uno, y projeto que es algo que llamamos a la existencia. Esa palabra la ha modulado la lengua y ahora hablamos de proyecto, entendido no solo como algo pensado, sino como realidad producida. Tenemos por tanto ante nosotros un triple itinerario estético que estamos invitados a recorrer sin poder llegar al final. Vale aquí la intuición de Heráclito para cuantos tratan de comprender lo humano: «Camina, camina, que nunca llegarás a los confines del alma. Tal es la profundidad de su $\log 0 s{ }^{21}{ }^{21}$

\section{Objectum: La belleza natural}

El hombre es ser racional, no es una pura inteligencia al estilo platónico o cartesiano, sino que es un viviente sensible, que requiere el ejercicio de los sentidos para conocer. Todo conocer tiene su punto de partida en la sensibilidad. Nada hay escrito en su alma cuando viene al mundo. Nada entra en ella sin la experiencia y sin pasar por la puerta de los sentidos. ${ }^{22} \mathrm{El}$ conocer humano se describe como una pasividad. Conocer es recibir, un cierto padecer, decía ya Aristóteles, no crear ni proyectar. A partir de esto Tomás presenta un panorama que afecta a la estética en su raiz objetiva. La inteligencia humana, en su asimilación de las cosas, en su grado más alto, juzga y ordena. Tomás distingue uni ordo que la razón humana no crea sino que solo desvela en el encuentro con las cosas: Est enim quidam ordo, quem ratio non facit, sed solum considerat, sicut est ordo rerum naturalium. ${ }^{23} \mathrm{La}$ apertura del ser humano al mundo que se le ofrece como objeto y su capacidad de desvelar la verdad de las cosas, de penetrar en su ser y sus relaciones, en el mismo ejercicio de poseerlas intencionalmente da origen a la aventura estética. Allí donde topa con el ser, su verdad y su orden logrado; topa con la belleza. El criterio para discernir las cosas bellas parte de la misma experiencia. El hombre siente ante la belleza cierto estupor, una especie de asombro, un agrado en su contemplación. Tomás propone como criterio de discernimiento de la belleza la intuición y el placer, que se dan en las cosas que los hombres designan como bellas: quae visa placent. ${ }^{24}$

Para Tomás de Aquino el itinerario a través del mundo es fundamental en el horizonte estético y tiene tres etapas, como ya había anticipado Platón en el Simposio, recordando la lección de amor y hermosura que Diótima habia dado a Sócrates, del encuentro con los cuerpos, al de las realidades que trascienden la materia, para Ilegar a la Hermosura vista cara a cara. ${ }^{25}$ En el realismo de Tomás estos tres momentos son el desvelamiento de la belleza en los entes, y su realización tanto en el orden categorial como en el trascendental.

El mundo real está transido de belleza. Preguntar dónde hay cosas bellas es más bien pregunta de ciego. La belleza se presenta por doquier. La pregunta debe ser invertida: idónde no está lo bello?. Una excursión a través del mundo natural, sublunar y celeste, como decían los medievales,

21 Cfr. Heráclito, Fragmente der Vorsokratiker, B, 22, Diels, FV.

22 Santo Tomás, ST, 12, 12: «naturalis nostra cognitio a sensu principium sumit; unde tantum se nostra naturalis cognitio extendere potest, inquantum manuduci potest per sensibilia»

23 Santo Tomás, In Lib. Ethic. Aristotelis, prol. 1.

24 Santo Tomás, $S T, I, 5,4$ ad 1.

25 Platón, Symposio, 210a-21lb. 
desvela en cascada las bellezas que encierra el universo. Tomás desvela el orden maravilloso del mundo y hasta piensa que hay toda una escala ascendente de perfecciones en los minerales, en cuyo vértice pone el oro, en los vivientes, sean plantas o animales, pero no hay cuerpo tan bello como el cuerpo humano ${ }^{26}$ Entre las afirmaciones de Tomás destaca ésta, la belleza más alta en lo corporal, aparte del cuerpo humano, es la del rayo de luz, Nihil autem videtur esse pulchrius quam radii solares. ${ }^{27}$ El encuentro con la belleza objetiva de la naturaleza se hace posible por la posición vertical del hombre, único animal erecto. El hombre es como un árbol con las raices hacia arriba, y como un animal pero con los sentidos en lo alto. La verticalidad es su privilegio. «La verticalidad le fue conveniente al hombre por cuatro razones. La primera porque los sentidos le fueron dados no solo para proveerse de lo necesario para vivir, como sucede en los animales, sino para conocer. De ahí que mientras los animales no se deleitan én las cosas sensibles mas que en orden al alimento y a la procreación, solo el hombre se deleita en la belleza...». ${ }^{28}$

Hay dos niveles en el ser de las realidades terrenas, que son asiento de la belleza. El primero es el orden físico, el de la realidad concreta, cl otro es el metafísico. Tomás ha analizado los elementos de la belleza en ambos, y ha dejado una lección imperecedera. En el orden de las categorías hay que afirmar que todas ellas son asiento de la belleza, pero no lo son todos los individuos. La aportación de Tomás en este campo consiste en haber recogido los diversos elementos que la tradición griega y medieval indicaba y haberlos reunido en verdadera síntesis. En un breve párrafo Tomás presenta las condiciones que requiere un ser concreto para merecer ser llamado bello: ad pulchritudinem tria requiruntur.. «Tres cosas se requieren para la belleza. En primer lugar integridad, o perfección, pues las cosas inacabadas o empequeñecidas son por eso mismo feas. También se requiere la debida proporción o armonía. Por último se precisa la claridad, de donde procede que las cosas que tienen colores nítidos se digan bellas». ${ }^{29}$ Estas tres notas son cumulativas, deben darse realmente en el ser físico para poder llamarse bello con toda propiedad. Para una mayor exposición de estas tres condiciones remito al lector al citado libro «Ser y belleza», que las expone con cierta amplitud. ${ }^{30}$

La presencia de las tres condiciones en un ser concreto propician al sujeto humano la experiencia de lo bello, le presentan el ser, cuius apprehensio placet, como dice Tomás con otra descripción de lo bello. ${ }^{31}$ Alberto Magno nos ha dejado la fórmula que completa desde el lado objetivo la definición aquiniana: «La belleza consiste en el esplendor de la forma sobre las partes proporcionadas de la materian. ${ }^{32}$

Hay en los seres otro nivel de realidad, el que le compete por su condición de ente, que prescinde de la materia. También en este orden Tomás de Aquino ha dejado una huella cultural imborrable. En otro estudio yo he indicado que Tomas en esta tarea de descubrir la constelación de las propiedades o epifanias del ente invita al recorrido de tres pistas, una ontologica, que despliega la

Santo Tomás, QD, De anima, a.1.

Santo Tomás, In Job, c. $4 I$.

Sato Tomás, ST, $l, 91,3$ ad 4 .

Santo Tomás, ST, I, $39,8$.

Cfr. A. Lobato, Ser y belleza, Herder, 1965, pp. 84-103.

Santo Tomás, ST, III, 27, 1 ad 3.

32 Cfr. Alberto Magno, De Pulchro, edic. Mandonnet, p, 427. 
res, otra antropológica, con el desarrollo del verum, y una tercera teológica, con la comprensión del bonum. En este análisis, el despliegue va dando diversas tríadas explicativas ${ }^{33}$. El problema de la belleza como propiedad trascendental del ser en Tomás de Aquino es un problema. Tomás se ha inspirado en la «Summa fratris Alessandris para acoger la doble relación antropológica que se destaca en lo bello, con el apetito porque agrada, porque lo sacia como el bien, y con el conocimiento porque la complacencia requiere la visión intelectual. Por esta doble referencia de lo bello puede decirse que es la síntesis de los trascendentales, que incluye a los anteriores y los supera. Si en las listas de Tomás no se incluye de modo claro, hay en su doctrina fundamento para una evolución y desarrollo completo. La belleza sigue al ser, y tal es el grado de ser lo es de su belleza. Tomás piensa con Dionisio que Dios es la belleza absoluta y de ella participa en modos diversos el mundo creado por Dios. ${ }^{34}$ En todo caso no cabe la menor duda de que la belleza va con el ser.

\section{Subjectum: La belleza espinitual}

El horizonte estético no se agota en el encuentro con las cosas que poseen y participan de la hermosura. El hombre, como ser racional, no solo está dotado por la naturaleza para desvelar el orden existente, sino posee un poder singular, el de crear un orden nuevo. Su inserción en el mundo no solo es pasiva, es sobre todo activa. Y en este poder se funda la capacidad de ampliar el horizonte estético.Hay una actividad humana que recae sobre el propio sujeto por la cual está capacitado para disponer de sí mismo. El ser en acto se proyecta a través de sus actos, y estos tienen el poder de modelar el proceso de desarrollo del propio sujeto. El dominio sobre el agere modela el sujeto, lo lleva a la perfección o lo envilece. Mediante la actividad que ordena los actos de la voluntad, lo que Tomás llama ordo quem ratio facit in operibus voluntatis ${ }^{35}$, el hombre tiene poder sobre sì mismo. Este es el campo humano por antonomasia. Nadie puede pasar de largo ante él. Hay un imperativo divino que se extiende al sujeto humano: «Hagamos al hombre» (Gen, 1, 26). Al hombre no le basta el ser que recibe de Dios, por el cual tiene un rango de dignidad y de belleza, sino está llamado a desarrollar su propio ser hasta llegar a ser lo que Gregorio Nisseno designa como «ser padre de si mismo».

Tomás de Aquino se ha ocupado ante todo de este campo en el cual se forja el hombre y se adquiere la medida de lo humano. El hombre puede tener por naturaleza y disposición una belleza corporal, cuando reune las condiciones que se requieren. No a todos le es dada. En cambio a todos es posible la belleza espiritual. Tomás ha empleado la mayor parte de obra teologal en indicar a los hombres este itinerario de conquista de la belleza espiritual. Las notas que se requieren para la belleza objetiva, -integridad, proporción y claridad-, se pueden dar por análogía en el sujeto

33 Cfr, A. Lobato «Fundamento y desarrollo de los trascendentales en Santo Tomás de Aquino», en «Aquinas», 34 (1991)pp. 203-222.

34 En mi libro ya citado «Ser y bellezo» yo he tratado de prolongar la lista de los trascendentales hasta incluir con todo derecho lo bello: pp. 104-144. En esa línea se situan otros estudiosos de este problema en Tomats: FJ. Kovach, Die Aethetik des hl. Thomds, Berlin, 1961; W. Czapiewski, Das Schöne bei Thonas von Aquin, Freiburg, 1964; L. Elders, La metafisica dell'essere, Roma LEV, 1995, pp-160-169. En cambio J.A. Aertsen, Medieval Philosophy \& Transcendentals. The case of Thonas Aquinas, Brill, 1996, opina que no se pucde demostrar que lo bello en Tomás vaya más alia de ser una species boni.

35 Santo Tomás, In I Ethic. Prol. n.l. 
humano, y así surge la belleza espiritual. «Pulchritudo spiritualis in hoc consistit, quod conversatio hominis, sive actio eius, sit bene proportionata secundum spiritualem rationis claritatem» ${ }^{36}$. Se da una belleza del alma, que es fruto del ejercicio humano de las virtudes, una conquista personal. Tomás propone como modelo a Cristo, el hombre en plenitud, en quien se da una cuádruple belleza: la que procede de su forma divina, por la cual es el esplendor de la gloria del Padre; otra la que brota de su plenitud de gracia y de verdad; la tercera es la que brota de su estilo de vida sin defectos y la cuarta es su belleza corporal, el más hermoso entre los hombres ${ }^{37}$ La hermosura de Cristo debe ser imitada y participada por los discípulos. El modo humano de conquistar la belleza es seguir el camino de la virtud. Tomás es el maestro de la teología moral, del humanismo cristiano. Toda virtud adquirida embellece al hombre y la da una nobleza singular, una cierta aureola que lo distingue y lo eleva. ${ }^{38}$

La belleza implica el esplendor de la forma, la luz y la claridad que refulge donde hay una huella del espíritu. Tomás aprecia en su justo valor la estructura racional del hombre, y por ello defiende que la belleza esencial procede de este fundamento, y que tal belleza se da ante todo en la vida contemplativa, en el ejercicio sapiencial. Las demás virtudes, en particular las morales, producen también belleza en el sujeto humano, pero solo por una cierta participación. ${ }^{39}$ La vida contemplativa será la vida eterna del hombre, mientras que las virtudes de la vida activa cesan con el final de la temporalidad.

Una vez que Tomás ha dejado en claro cuál sea el camino de la conquista de la belleza y del esplendor en el orden espiritual, la belleza del alma, que no puede darse sin las virtudes, añade algo tocante a las virtudes morales. Todas ellas contribuyen a la conquista de la belleza espiritual. Pero entre todas se atribuye de modo especial a la templanza, porque al regular los placeres del tacto y del gusto, hace posible un orden de sumisión de las fuerzas instintivas del hombre a la razón. El hombre racional debe ser honesto. La templanza refrena los excesos de las pasiones. Así como los vicios contrarios a la templanza afean, deshonran al hombre, la castidad y la templanza lo embellecen. «Quamvis pulchritudo conveniat cuilibet virtuti, excellenter tamen attribuitur temperatiae». ${ }^{40}$ La belleza lleva consigo esplendor, claridad. Los vicios de la intemperancia, aún siendo los que menos razón tienen de pecado, son los que en la común opinión más afean al hombre y le rebajan a una condición que Tomás describe como «bestial». «In virtutibus autem moralibus invenitur pulchritudo participative, inquantum scilicet participant ordinem rationis; et praecipue in temperantia, quae reprimet concupiscentias maxime lumen rationis obscurantes. Et inde est quod virtus castitatis maxime reddit hominem aptum, ad contemplationem, inquantum delectationes venereae maxime deprimunt mentem ad sensibilia» ${ }^{41}$.

36 Santo Tomás, ST, II.II, 145, 2.

37 San Tomás, In Psal. 44, 2.

38 Santo Tomás, In IV Sent, d.-33,q.3.art. 3 ad 1. ST, II,II, 142, 4.

39 San Tomás, ST, II.II. 180, 2 ad 3: «Pulchritudo consistit in quadam claritate et debita proportione. Utrumque autem horum radicaliter in ratione invenitur, ad quam pertinet et lumen manifestans et proportionem debitam in aliis ordinare. Ideo in vita contemplativa, quae consistit in actu rationis, per se et essentialiter, invenitur pulchritudo... In virtutibus autem moralibus invenitur pulchritudo participative, inquantum scilicet participant ordinem rationis».

40 San Tomás, ST, II.II. 141, 2 ad 3.

41 Santo Tomás, ST, II.II, 180, 2 ad 3. 
Tal es el itinerario tomista de la forja de la belleza cuando la acción recae sobre el propio sujeto y logra modelarlo conforme al ideal de humanidad y al ejemplar cristiano del hombre nuevo en Cristo. ${ }^{42}$

\section{Projectum: La belleza artistica}

Más allá del obrar humano que es el eje de la humanización, está el hacer, la actividad del hombre que recae sobre la materia exterior para darle nuevas formas. ${ }^{43} \mathrm{Al}$ hombre se le ha dado no solo la mente, sino también la mano para que modele la materia exterior conforme a sus exigencias. Por esta actividad el hombre es disignado como homo faber.Su acción recae sobre la realidad circundante, sobre la materia en la cual el hombre es capaz de infundir nuevas formas. Esta actividad da origen a los productos humanos. Mediante la mano el hombre fabrica instrumentos que le sirven para el dominio del mundo, para la fabricación de cuanto puede ser útil y responde a sus necesidades: alimento, vestido, casa, cultura. Mediante esta actividad el hombre origina la cultura, la cual a su vez influye en el mismo hombre.

La vida estética encuentra en esta actividad un amplio dominio y señorío. Los productos del hombre son los que el propio hombre añade a la naturaleza. Esta actividad es creativa, origina lo que aún no existe. El hombre, émulo del Dios creador y de la naturaleza, por via de imitación, se convierte en artista. Tomás conoce esta actividad, la analiza y en ella encuentra otro horizonte de la belleza. Todo parte del hombre imagen de Dios. Dios crea el mundo y por ello es artista en sentido propio, puesto que tiene las ideas de las cosas que produce, «en Dios existe el arte en sentido propio» ${ }^{44}$. Es el verdadero artista a quien compete crear. Ya en la vida ad intra hay un arte divino, y lo hay en sus obras ad extra. La naturaleza participa de esta capacidad creativa de Dios, es su obra y por ello tiene una potencia inagotable de producir nuevas formas.

El hombre, situado en medio de la naturaleza, pero hecho a imagen de Dios, es capaz de una cierta creatividad. No puede producir de la nada, pero tiene en su interior libertad de espíritu, dominio de sus actos y por ello, a su modo da origen a un mundo a su medida. Así nace el proyecto y con él el arte. Tomás describe esta actividad como un ordo quem ratio facit in rebus exterioribus constitutis per rationem humanam. ${ }^{45} \mathrm{El}$ hombre imagen de Dios, el hombre inserto en la naturale$\mathrm{za}$, pero emergiendo sobre ella, por ser capaz de conocerla, se hace capaz del proyecto sobre el mundo. Supone la materia, necesita de ella, pero es capaz de imponerle las formas. Este poder o facultad se llama arte, que no solo se ocupa de las cosas necesarias para la vida del hombre, sino también de producir la belleza. Cuando logra unir lo útil y lo bello, cuando pone la técnica al servicio del hombre interior, logra la belleza objetivada. ${ }^{46}$

Tomás ha dedicado mucha atención al arte, a su fudamento en la humana razón, a su poder de servicio y de promoción del hombre, a su capacidad para multiplicar la belleza. Esta actividad da

42 Cfr. A. Lobato, Dignidad y aventura humana, Salamanca, 1997. Esta obra plantea el problema de la conquista de la dignidad, desde la base de la persona, mediante el ejercicio de las virtudes.

43 Cfr. A. Lobato,» El problema del hacer humano», en «Salmanticensis», 13 (1966 pp. 283-325.

44 Santo Tomás, SCG, II, 93.

45 Santo Tomás, In I Ethic. Aristotelis, I, Prol, n, 2

46 Horacio lo ha expresado de modo imperecedero: Omne tulit punctum qui miscuit utile dulci, Epist. Ad Pisones, 
origen a la cultura en sus diversos elementos del conocer y del poder, de las letras y las artes. $\mathrm{La}$ materia que se somete al arte es la totalidad de là realidad a su alcance, en primer lugar el cuerpo humano, que puede ser educado y modelado, luego la lengua que implica la mayor creatividad humana. A través de la voz y el sonido tiene origen la poesía, la retórica, el teatro con todas sus formas, la música y el canto. De los objetos de los sentidos, como la vista, brota el arte que se apoya en la luz y los colores, la pintura, el dibujo. Las artes del comer, del vestir, del vivir en la ciudad, sirven a las necesidades del hombre en sociedad. Tomás ha tenido en cuenta la capacidad de ordenación de la razón mediante el ejercicio de las manos, y así de poblar el mundo de nuevas realidades que sirven al hombre y expresan el poder de proyectar la belleza. ${ }^{47}$

La capacidad proyectiva del hombre es inagotable, y es necesaria. Pero debe ser regulada por las virtudes morales, que no solo hacen la obra buena sino bueno al hombre.

$* * *$

Tal es, en líneas generales, el horizonte estético que Tomás presenta y organiza de modo admirable en el ob-jectum, sub-jectum y' pro-jectum. Se advierte sin esfuerzo la primacía de lo humano. El hombre es apto para la contemplación y para desvelar la belleza, como lo es para producirla. No hay inconveniente en fundar la capacidad estética del hombre en su poder de imitación. El hombre imita la obra de Dios, imita la naturaleza mediante el arte. La creación le compete solo en modo secundario. Pero no se puede reducir la imitación a algo externo, a una copia, sino a una lectura profunda de la función de la forma en la materia y a la capacidad de colaborar en la obra de Dios para realizar la finalidad del mundo, que es el servicio al hombre.

La tarea más importante entre las actividades humanas no es la la del homo faber, la de producir objetos útiles o bellos, sino la del homo sapiens, la que brota de la misma forma humana y se ocupa de lo que es más propio del hombre, en cuanto ser racional. El hombre está llamado a la conquista de la belleza en su plenitud personal. Para ello puede disponer todas las demás actividades, las productivas y las cognoscitivas. La belleza moral le ayuda de modo especial, la contemplación de lo bello objetivo le dispone para la imitación del creador y de la naturtaleza. Al hombre como señor y dueño de su libertad se le pide un desarrollo integral en la conquista del orden trascendental del ser, de la unidad, la verdad y la bondad. Por esa vía está en camino de alcanzar la plenitud y el gaudium de veritate et bonitate, la belleza, la fusión con su mismo horizonte estético.

\author{
Abelardo Lobato, $\mathrm{OP}$ \\ Facoltà di Teologia di Lugano \\ Via Nassa, 66 \\ CH-6900 LUGANO \\ SUIZA
}

